\title{
Decentralized Network Governance: Blockchain Technology and the Future of Regulation
}

\author{
Andrej Zwitter ${ }^{1 *}$ and Jilles Hazenberg ${ }^{2}$ \\ ${ }^{1}$ Data Research Centre, Faculty Campus Fryslân, University of Groningen, Groningen, Netherlands, ${ }^{2}$ Independent \\ Researcher, Groningen, Netherlands
}

Advancements in the digital domain, for example, in blockchain technology, big data, and machine learning, are increasingly shaping the lives of individuals, groups, organizations, and societies. These developments call for effective governance to protect the basic interests and needs of these actors. Simultaneously, the very nature of governance is also changing. Policy-making is increasingly moving away from top-down governance by the state toward more horizontal modes of governance. This paper reviews the literature on governance theory in order to conceptualize governance as a mode of decentralized, networked regulation. We argue that the current dominant modes of governance are inadequate in understanding governance in the digital domain and are poorly equipped to conceptualize novel forms of governance such as decentralized autonomous organizations (DAOs). Therefore, this study proposes a new mode of governance based on the regulation of new power relationships between the state and actors in the digital domain. This model further explores the role that blockchain technology can play in what we term decentralized network governance.

Singapore University of Technology and Design, Singapore Michael Cooper, Independent Researcher, Denver, United States

*Correspondence: Andrej Zwitter a.zwitter@rug.nl

Specialty section: This article was submitted to

Blockchain for Good, a section of the journal

Frontiers in Blockchain

Received: 28 October 2019

Accepted: 27 February 2020

Published: 25 March 2020

Citation:

Zwitter A and Hazenberg J (2020) Decentralized Network Governance: Blockchain Technology and the Future of Regulation. Front. Blockchain 3:12.

doi: 10.3389/fbloc.2020.00012

\section{INTRODUCTION}

Innovations in the digital domain are increasingly shaping the daily processes and interactions of individuals, educational institutions, companies, and governmental organizations. However, the theoretical frameworks of governance that are being employed concerning these have not advanced at the same pace, and fall behind in terms of regulating new technologies and their societal impact. Blockchain is one of these new technologies and is widely seen as a "swiss multi-tool" that can provide solutions for many emergent problem areas such as digital identity, data ownership, privacy, and even future decentralized decision-making (see section Mode 3 - Decentralized Network Governance and Blockchain Technology on DAOs). In this paper, we tie together the literature on governance and social network theory in order to develop a novel conception of governance. We argue that this novel conception is better at accommodating new and increasingly dominant forms of technological governance such as through blockchain technology. Moreover, we propose that it addresses governance challenges caused by blockchain technology in a more effective way. The conception of decentralized network governance relies on social network theory.

The manner in which societies are and can be effectively governed has changed. Because of the pressures of globalization, functional differentiation, and technological specialization, governance processes and mechanisms have become increasingly decentered, horizontal, and, ultimately, 
networked (Rhodes, 1996, 1997; Kooiman, 2003; Van Kersbergen and Van Waarden, 2004; Bevir, 2010, p. 1-93). Policy-making no longer relies primarily on the exerted power of a single actor, which has traditionally been the state. Instead, interactions and societies are becoming increasingly governed by networks that comprise a diverse set of public and private actors. It has also been acknowledged that the digital era is increasingly fragmenting the playing field between governance actors (Murray, 2011). These changes necessitate an updated conceptualization of what governance is, as well as a consideration of what extent new technologies like blockchain technology [and also digital ledger technology (DLT)] can contribute to effective and legitimate governance mechanisms.

The aim of this study is to merge the literature on governance with social network theory, in order to conceptualize a new approach to governance: decentralized network governance. Within the governance literature, policy-making is becoming increasingly conceptualized in terms of different modes of governance. These range from Westphalian commandand-control governance to decentered, horizontal, and self-referential modes of governance. In order to envision governance effectuated by digital networks in general and by blockchain technology specifically, we turned to network theory. This theory offers an appropriate concept of societal power in a networked system, of which distributed ledgers and the decentralized nature of blockchain technology are an example.

Whereas traditional and new modes of governance rely on the identity and roles of specific actors, blockchain technology requires a re-appreciation of the powers exerted by different actors. In this study, we used Manuel Castells's conception of network power in order to analyze new power relationships (Castells, 2000, 2011). Traditional modes of governance fail to appreciate changes in power relationships that result from the emergence of new actors, practices, and relationships. We argue, however, that such consideration is essential for constructing governance in the digital domain.

This paper consists of four sections. In the first section, the terms datafication and blockchain technology are introduced. In the second section, governance literature is reviewed and dominant modes of governance are conceptualized. In the third section, arguments are put forward concerning why these modes of governance are inadequate in terms of effectively governing the quasi-theoretical conceptions introduced by DLT and blockchain technology. The fourth section offers the first methodological clues for the analysis of network governance, based on social network analysis. These methods will allow for better decisions to be made regarding how to design and disseminate power relationships into technological solutions, which require oversight and regulation.

\section{DATAFICATION AND BLOCKCHAIN TECHNOLOGY}

The creation, collection, dissemination, and distribution of all sorts of information in the digital domain rely no longer solely on social processes but increasingly on technology. An algorithm determines the updates you see on Facebook, press agencies rely on data analysis to assess the newsworthiness of information, and social networking sites and blogs are digitally scraped for information to target advertisements at individuals (Goodman, 2015). Blockchain technology is promising to reform digital currency, in order to improve logistics and help manage digital identity in a decentralized and trustless manner (Zwitter and Boisse-Despiaux, 2018). These algorithms are primarily developed and employed by private actors.

Information is crucial for social coordination, i.e., for governance, and digital data are the modern embodiment of information. This means that the conditions of the digital domain affect governance substantially. Artificial intelligence (AI) and blockchain technology are among the most prominent exemplifications of this phenomenon. More and more of our social interactions are being shaped by these technologies. The political and economic worlds are also becoming increasingly structured and regulated by the effects of AI and DLT, increased connectivity, and the services surrounding them. Researchers and professionals alike are prophesizing a data revolution that is as equal in impact and disruptive in force as the industrial revolution.

The potential uses and value of AI and DLT are indeterminate and potentially limitless. This indeterminacy is arguably one of the driving forces behind the fast pace of innovation in these fields. Academics, data analysts, and corporations are in the process of finding value in data and its decentralized management. They are also looking into ways that data sets can be operationalized and linked and are trying to determine what can be learnt from such analyses (Manyika et al., 2011; Provost and Fawcett, 2013; Chandler, 2015; Metcalf and Crawford, 2016).

Blockchain technology and DLT can be defined as decentralized and trustless ledgers, recording transactions across a peer-to-peer network. These features create the potential to provide transparency as well as accountability. Such technologies could impact not only the financial sector (e.g., Bitcoin, Libra) but also diverse fields such as supply chain management, digital identity, smart contracts, voting (e.g., liquid democracy), health records, water management, and much more.

To summarize this in a simplified manner, a blockchain is a decentralized database that stores a registry of assets and transactions across a peer-to-peer network. The "asset" may not only be money or transactional information, but also information regarding ownership, contracts, goods, and any other information (Warburg, 2016). A blockchain does not duplicate the value that is transferred, like other peer-to-peer networks, but instead, it registers that a value has been transferred from one actor to another. Moreover, DLT does not require any central control system, and it stores the transaction history in blocks of data that are cryptographically locked together. As it is replicated on every node in the blockchain network, it becomes an immutable and transparent historical record of all transactions (Balva, 2017).

Blockchain is based on a consensus mechanism. This mechanism basically relies on "hashing" and a type of "proof", e.g., "proof of work," "proof of stake," and other proofs. Hashing is the process of creating a digital fingerprint of any sort of 
information shared in the transaction. The hash is a way of verifying the authenticity of the transaction. This allows users to identify whether data have been tampered with.

The technical specifications of DLT systems are becoming increasingly varied in nature. This shows that often-highlighted features of blockchain technologies, such as immutability, transparency, and trustlessness, are in fact design features rather than sine qua non-conditions (Zwitter and Boisse-Despiaux, 2018). However, one can say that blockchain is a technology that lowers the uncertainty regarding transactions between parties that do not otherwise share trust. The idea of a "trustless" technology means that DLT, by nature of a validated ledger shared across all peers, reduces the uncertainty of not having recourse if something goes wrong with a transaction. Since DLT allows the tracing of every transaction, from the beginning until it is validated and added to the blockchain (or similarly structured ledgers), users can verify whether an error has happened, and also where the error has occurred.

A particularly interesting development that the emergence of blockchain technology has brought with it is the concept of DAOs (decentralized autonomous organizations). Blockchain technology and Bitcoin have been developed to make traditional financial governance mechanisms obsolete, as its developer Satoshi Nakamoto (mysteriously or pseudonymously named) envisioned (Nakamoto, 2008). The technology was designed with a specific governance model in mind, and this becomes more visible when reviewing the discourse on DAOs (Chohan, 2017). DAOs can be defined as "non-hierarchical organizations that perform and record routine tasks on a peer-to-peer, cryptographically secure, public network, and rely on the voluntary contributions of their internal stakeholders to operate, manage, and evolve the organization through a democratic consultation process" (Hsieh et al., 2018). The DAO thereby has two governance components. The first is the internal governance component, which is characterized by non-hierarchical modes of governance and has quasi-democratic features. These features are quasi-democratic rather than democratic because there is no guarantee of the principle "one person, one vote." For example, an actor can accumulate more votes than others, thus tipping voting balance in its favor. Dependent on its design, the weight of voting rights can be based on several different parameters. Within the DAO, voting weight can be dependent on the ownership of tokens, the weight can be capped at certain levels, etc. (Quiniou, 2019, p. 84). The external governance component is the reliance on clusters of servers and individual nodes for the functioning of the network and decision-making. In essence, actors can exert undue influence on decision-making, and in a stronger way than other actors, if they control more nodes and server capacity. Furthermore, developers themselves can offer code upgrades through open participation and self-selection, and miners can vote on protocol changes based on computing power (Hsieh et al., 2018).

From a policy-making perspective, big data analytics, AI, and DLT have drastically changed the core concepts of governance. Two key effects have been observed:

Actors and roles: New actors are appearing, both on the national and international stage. Moreover, the roles and relationships that actors have developed between each other are changing (Zwitter, 2015). New actors who are bridging the digital with the physical world are emerging as increasingly powerful players on both the national and international stage. These are not just the big corporations, such as Google, Facebook, and BuzzMetrics, which are dominant in collecting and analyzing big data, but also smaller interest groups who are gaining traction through the quasi-democratizing effect of blockchain technology and the equalizing effect of digital communication. Hacking collectives such as Anonymous and LulzSec are being recognized as powerful players not to be ignored. Furthermore, the cyber domain has established new and changing roles of different governance actors. Big data generators, collectors, utilizers, blockchain miners, server providers, etc., are new roles that are shaping the relationships between actors. A good example of the changing effect that this has had on relationships between actors is "the paradox of individuality in big data" (Richards and King, 2013). Although the individual plays a relatively insignificant role within the larger pool of data, i.e., as a generator and utilizer of data and authenticator in the blockchain, the individual can potentially become powerful. Examples of this power (of the individual as the utilizer of technology) are the numerous hacks that have affected the blockchain community, e.g., the Mt. Gox hacks, BitStamp hack, Bitcoinica hacks, etc.

Power relations: These new actors and changing roles are constituting new and changing power relationships. In particular, actors such as tech corporations and organizations involved in blockchain technology, like the Ethereum or IOTA networks, have become increasingly powerful because ownership is in the hands of those who develop the means, collect the data, and repurpose the tools (Richards and King, 2013, p. 44). In the domain of big data, collectors (which also include many state agencies) determine what is collected and stored, and for what period of time. Big data utilizers, who are predominantly private corporations, operationalize data by defining and re-defining it for purposeful analysis. Small groups and individuals operating as hacktivists, cyber criminals, and cyber terrorists can challenge the power of corporations and states. The power relationships between these actors influence social coordination. These are also no longer confined to national jurisdictions because the digital realm spans the entire globe. The source of power thereby changes ${ }^{1}$. As we will see below, the different kinds of relationships (nodal relationships between actors) can become very relevant in the exercising of power.

The shift in power relationships effectuated by the digital transformation of big data, blockchain technology, and AI has been tremendous. Technologies provided by private corporations, and the data bought from large data collectors, are being increasingly replied upon by many sectors such as intelligence agencies, the public and private banking system, and political parties. In effect, the legal, economic,

\footnotetext{
${ }^{1}$ Power is here conceived as relational (Dahl, 1957). Conceived as a relation, power exists in coordination and the ability of an actor to command that coordination. A single actor cannot be powerful in and of itself, it is in the ability to command others that she has power.
} 
political, criminal, and military domains have undergone tremendous change due to the digitalization of the world. As we will show, traditional modes of law and governance are doing little to conceptualize, control, and coordinate these shifts in power.

In general, these emergent technologies, and blockchain technology in particular, are already tacitly or explicitly imposing their own governance norms, when seen from the perspective of Lessig's "Code is Law" (Lessig, 2000). However, closer investigation is required in order to ascertain whether these imposed norms of governance also need regulation and governance themselves. There is a need to strike a balance between the new power distributions and the tacit governance norms and structures imposed by technology, vis-àvis the existent normative framework and governance structure surrounding our democratic principles. However, the changing roles of governance actors and, thereby, the available mechanisms of governance require reconceptualization. This is because, for instance, legal norms are notoriously lagging behind in relation to the pace of technical innovations, but also because the potential illegitimate uses of big data pose a great threat to fundamental rights and require some form of regulation and/or oversight. Public actors, traditionally conceived as protectors of public interest, lack the capabilities to effectively govern the spaces created by many technological innovations. Moreover, public actors have been subject to critique for the widespread collection of the data of individuals, and the leaks of such data as well. The next section will explore the concept of governance and its dominant modes.

\section{MODES OF GOVERNANCE}

The digital domain requires regulation and governance in order to establish a more legitimate, and ultimately productive, balance of power. This raises the question of what the best way to conceive and conceptualize such norms and rules is. In this study, we have taken a broad perspective of governance, avoiding bias toward specific modes of governance.

Governance itself is an elusive concept, highly complex and contested in literature (Kooiman, 2003; Van Kersbergen and Van Waarden, 2004; Levi-Faur, 2012; Colombi-Ciacchi, 2014). In our study, we use a unifying conception of governance based on Levi-Faur (2012). Levi-Faur (2012, p. 7-8) defines governance as "signifier of change" in policy-making. By signifying different changes in policy-making, governance opens up "new ways, new concepts, and new issues for research" (Levi-Faur, 2012, p. 7-8). This conception of governance as a signifier of change offers a comprehensive perspective on policy-making as subject to "continuous change of patterns of interaction and relations among actors" (Sand, 2004).

Governance is often depicted by distinguishing between "old" and "new" governance (Rhodes, 1996, 1997; Mayntz, 2003; Bevir, 2010; Lobel, 2012). "Old" refers to hierarchical structures, mostly of state institutions. "New" refers to the emergence of more horizontal modes of policy-making, which have arisen due to the pressures of globalization and the functional differentiation of sectors of society. However, given that neither old nor new types exclude each other, they often co-exist in practice and a clear temporal distinction between them cannot be located. We refer to these types of governance as Mode 1 and Mode 2 governance. The current assessment focuses on two aspects of Mode 1 and Mode 2 governance: roles and power relationships. Governance roles are understood as the ability to participate in policy-making at any stage. Power relationships refer to the relative power that an actor, or a certain role, has over other actors within policy-making and its enforcement. Within different modes of governance, different aspects of power relationships are deemed relevant. A useful analogy of this is the power that a policeman has standing at an intersection commanding traffic: power can be derived from his uniform, the perception of the drivers, or of him blocking the road (Dahl, 1957). Similarly, modes of governance regulate or coordinate different aspects of power relationships based on what is deemed the relevant aspect of power.

\section{Mode 1 Governance}

Mode 1 governance, or "old" governance in the literature, refers to governance carried out primarily via the hierarchical command-and-control structures of the state and other public hierarchies (see Figure 1). This means that it relies on authoritative institutions to make policies through the enforcement of hard law. Rooted in Westphalian notions of nation-states, this mode of governance is often legitimized through justificatory strategies resting on public sovereignty and public input in political decision-making (Scharpf, 1999). Therefore, Mode 1 governance is inherently political and institutional.

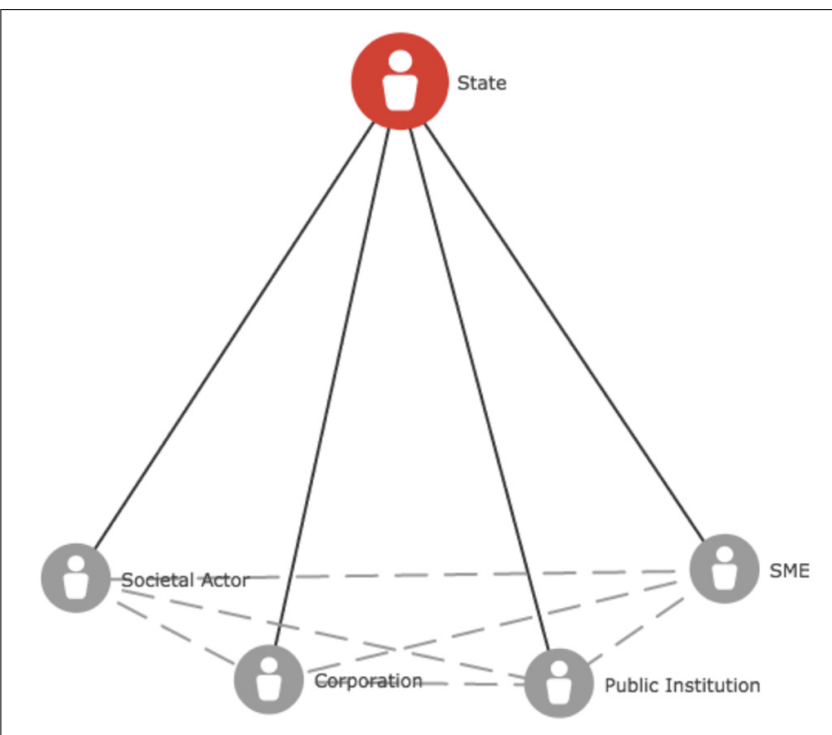

FIGURE 1 | Hierarchical command-and-control policy-making via the state. Within Mode 1, the state is sovereign and legitimate in commanding and controlling societal actors (both public and private; among private actors, for example, social groups and small and medium enterprises, SMEs). The identity of actors is perceived as the relevant aspect of power. Power relationships are vertical because they base themselves on the identity of the state as sovereign and legitimate. 
Furthermore, this mode of governance can be interpreted as identity-based. Within identity-based governance, roles are assigned to and/or performed by actors based on who these actors are, i.e., their identity. For example, Mode 1 governance locates the authority to perform tasks of policy-making, or the delegation thereof, with state organs because of who the state is. This means that the state's identity is seen as being an authoritative and legitimate public body, acting as sovereign over a territory and as the source of law and policy. Intermediary institutions perform governance roles only through delegated authority by the state.

Given the relative clarity of governance structures within Mode 1, the relevant aspects of power relations are equally clear. The authority to make, implement, and enforce policies lies with the state or those that it delegates to do so. Power is static because authority is permanently assigned to an actor, based on its identity. The relevant aspect of a power relationship is thus the identity of the actor capable of commanding others. Moreover, power relationships are governed via structured governance mechanisms, by predominantly assigning rights to weaker parties and duties to stronger parties. The static nature of power and structured conception of power relationships are explained by the fact that relationships between individuals, organizations, societal actors, corporations, etc. are mediated and governed via the state as the dominant hierarchical authority in policy-making. A good example of this is the relationship between human rights and the duty of the state to protect them.

\section{Mode 2 Governance}

Mode 2 governance, or "new" governance, contrasts with these distinct Westphalian structures of policy-making. It represents a move away from the vertical command-andcontrol structures of the state toward more horizontal modes of policy-making (see Figure 2). This approach creates a more level playing field between societal actors, both private and public. Authority is not necessarily acquired by identity but rather through performance, knowledge, and expertise. Publicprivate partnerships, policy networks, and private governance all reflect the nature of a world in which the state is arguably no longer the central governing authority (Rhodes, 1997; Van Kersbergen and Van Waarden, 2004). Examples of Mode 2 governance are diverse, but include public-private partnerships working toward the achievement of policy goals that private sector agents are trying to realize more effectively and efficiently through self-regulation. Other examples of areas

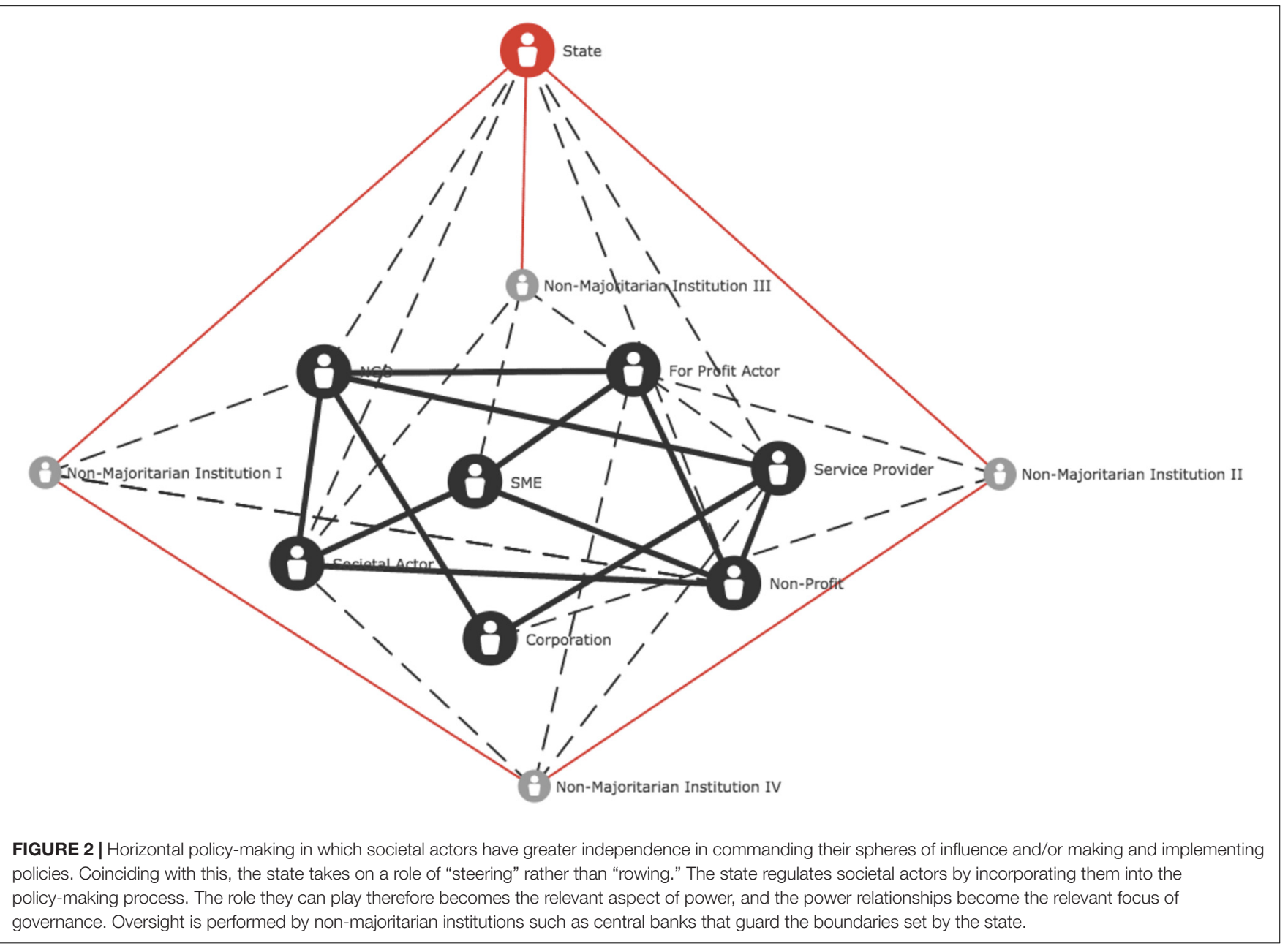


where Mode 2 governance mechanisms apply are soft law, negotiation, compromise, competition, codes of conduct, and other corporate sectoral agreements on standards of production or quality. As such, Mode 2 governance changes the roles and power relationships of and between actors involved in policymaking or subject to these policies. While not being necessarily unified, different forms of Mode 2 governance are role-based in the distribution of governance tasks, as opposed to identitybased.

Role-based governance implies that governance tasks and mechanisms are assigned to and/or performed by actors because of the role they can perform, to achieve a desired policy goal within a specific domain. Policy goals and corresponding benchmarks become prominent tools in steering policy-making in specific directions. For instance, a public institution sets goals in a specific policy domain and delegates the achievement thereof to private or corporate actors. These actors are perceived as being more capable of efficiently and expertly delivering the desired goal in this domain. In other domains, the roles of the same private and corporate actors might be completely different. This explains why Mode 2 is not identity but role-based, as the examples below illustrate:

It should be noted that the distinction between Modes 1 and 2 governance is not always clear in practice. Many hybrid forms exist that borrow elements from both modes. The most prominent is multi-level governance, predominantly employed to describe policy-making within the European Union. It relies on both Mode 1, i.e., hierarchical commands from a public authority, and Mode 2, policy networks and the involvement of private actors (Mayntz, 1998). Mode 1 governance is increasingly dismantled at the level of the state, while simultaneously reconstructed at the regional and international level in combination with Mode 2 governance (Van Kersbergen and Van Waarden, 2004).

With a view to Mode 2 governance, one can see that actors who are frequently engaged in the field of blockchain and DLT take on a variety of different roles. An interesting case that illustrates this is the call for regulation of initial coin offerings (ICOs) and similar crypto-securities. These ICOs can be described as cryptographically secured tokens that represent a token owner's bundle of rights and obligations vis-à-vis a token provider. They are issued by a token provider and registered on the blockchain as a source of income for their projects. In the last few years, such ICOs have come under increasing public scrutiny as concerning their role as financial securities under US and EU regulations. There have also been frequent fraudulent uses of ICOs, and these have become a contested issue in policy and academic debates (Hacker and Thomale, 2018). In terms of our typology, this shifted the debate around ICOs from being an unregulated space into the realm of Mode 2 governance, with governance ranging from moderate self-regulation to non-autonomous self-governance. It remains to be seen whether states deem it necessary to enforce governance in the field of crypto-securities, even by means of Mode 1 governance.

\section{MODE 3-DECENTRALIZED NETWORK GOVERNANCE AND BLOCKCHAIN TECHNOLOGY ${ }^{2}$}

Constructing the governance of the digital domain requires conceptualizing the relevant aspects of power relationships within this domain vis-à-vis Mode 1 and 2 governance. It is not surprising that the digital domain, and especially blockchain technology, cannot be effectively governed through either mode of governance. This is firstly because the emergent new roles and power relationships in the digital domain are neither hierarchical nor horizontal. Instead, they are fluid, with different roles and power relationships often residing in a single, anonymous, actor. Secondly, blockchain technology enables trustlessness, whereas trust is fundamental to the functioning of both Mode 1 and 2 governance. This section will address the first consequence briefly, before providing the stepping stones for the conceptualization of decentralized network governance (Mode 3).

Modes of governance rely on conceptions of the relevant aspects of power relationships to be governed. In relation to the digital domain and blockchain in particular, power must be conceptualized as fluid, as different actors perform different governance roles within different contexts. Also, there are times when the networks through which roles are distributed operate as governance actors themselves. As identities and roles are no longer central to the exertion of power in social coordination, their place has been taken by new forms of power and hence require new forms of governance. Castells's writing on network power (mentioned previously) notes that there are four forms of power specifically related to networks: networking power, network power, networked power, and network-making power. We can see that these relate closely to the digital domain and blockchain technology (Castells, 2011) ${ }^{3}$ :

- Networking power: the power that actors and organizations have that constitutes the core of the network. This power pertains to the ability to include and exclude others, and thereby controls the makeup of the network.

\footnotetext{
${ }^{2}$ Within governance literature, Mode 2 governance is sometimes depicted as "network governance." Within this strain of governance literature, the "network" is employed primarily as metaphor to exemplify the increasingly horizontal structures of Mode 2 governance and mechanisms of compromise and negotiation. We refer to decentralized network governance as the governance of a network (e.g., a blockchain network) through a network (the multiplicity of actors that exert power in continuously changing roles and relationships). Moreover, literature that describes Mode 2 governance as "network governance" often focuses on the relationships and mechanisms of coordination within institutions, for instance, regulatory agencies or public administrations. The present conceptualization does not confine itself to such a limitation. See Klijn (2008); Koppenjan and Klijn (2004), and Lewis (2011).
}

${ }^{3}$ Manuel Castells conceptualizes networked power as the dominant form of power exerted within modern networked societies. This is not the time or place to argue for or against this conceptualization of societal powers that structure modern societies. We employ these forms of network power as they directly relate to new powers that emerge within networks. The cyber domain is thus conceived as network, and its most prominent exemplifications are literally so without necessarily conceiving of societies themselves as networks. 
- Network power: the power that results from the standards required to coordinate interactions. This primarily concerns the imposition of rules within a network.

- Networked power: the power that actors have over one another within a network. This power mimics traditional conceptions of power but the way in which it is exerted differs per network.

- Network-making power: the power of an actor or organization to constitute or re-program a network according to its values and specific interests.

The employment of traditional modes of governance threatens to undermine the benefits of technological innovations such as blockchain and DLT. In particular, overregulation or the application of inadequate mechanisms often reduces the potential benefits of digital technologies. Consequently, this might produce more negative outcomes than positive ones, seeing as a mismatch between regulations and intended governance norms of technological solutions could produce the appearance of regulation without actually having adequate substance. Alternatively, overregulation might be obsolete when trust is not an issue, as is the case with blockchain-enforced governance.

The hierarchical governance of big data actors and states can either miss their targets, because the digital realm is not necessarily confined to territories, or tamper with innovations that might benefit societies. It is, for instance, commonly accepted that "code changes quickly, user adoption more slowly, legal contracting and judicial adaptation to new technologies slower yet, and regulations through legislation slowest of all" (Brown and Marsden, 2013, p. xv). Single actor solutions should therefore be rejected. Mode 2 governance can undermine the potential benefits of blockchain-based governance as its distribution of governance responsibilities cannot, as we have seen, be readily applied to governance structures established by blockchain technology. The integration of actors into governance mechanisms, based on their ability to achieve policy outcomes, runs the risk of privatizing oversight into the hands of those with the most power.

We propose a novel network approach to governance that is more tailored to the decentralized nature of governance structures, and which can generally be found in blockchain solutions and DAOs more specifically. Our approach of decentralized network governance seeks to distribute governing tasks according to capability and exerted power, on a fluid basis. This implies that governance tasks are distributed neither on the basis of the identity of actors nor on the basis of the role they can perform in the governance process. Given that different actors perform multiple roles within blockchain structures, often simultaneously, the relational nature of power is fundamental in this conception of governance. Within a governance network, a relational conception of power necessitates fluidity in governance tasks. The distribution of power becomes variable and dynamic dependent on the specific relation between two or more actors (see Figure 3).

Within decentralized network governance, roles vary according to the nature of the network and the relations within it. This requires that the distribution of governance tasks,

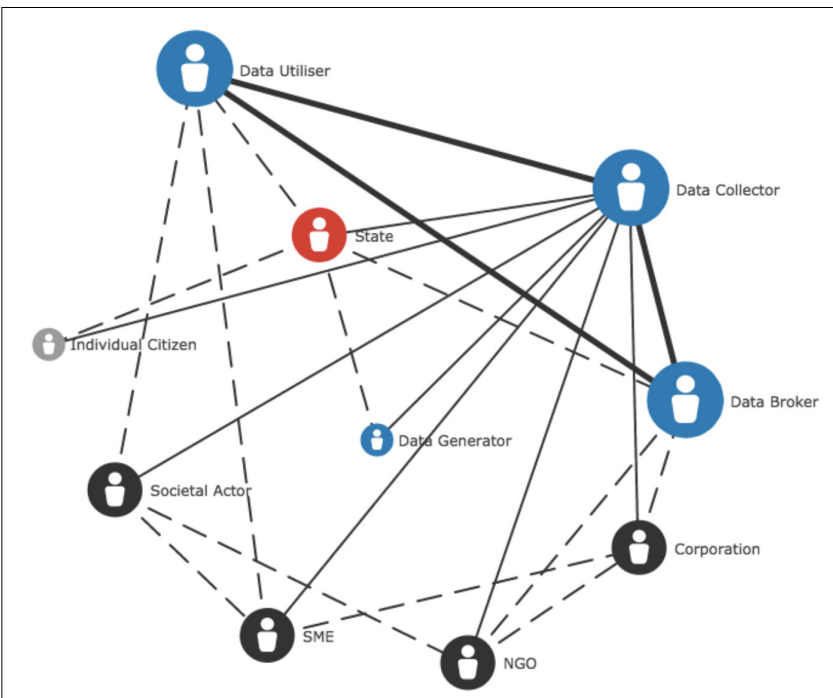

FIGURE 3 | Within the digital domain, and more specifically the domain of digital network providers, the state has limited powers and new actors emerge. These new actors command others through network-making and networked power, in a multitude of continuously changing relationships. Individual ownership of governance is limited. Governance over and within this network is thereby differentiated. This problematizes that power is dispersed throughout the network and is dependent on clusters/alliances of actors that can change per topic.

rights, and obligations are sensitive to relationships of power between actors. Governance mechanisms must be flexible. Moreover, as new aspects of power relationships become relevant in blockchain-based solutions, such as those concerning server providers, miners, etc., governance mechanisms should address these. Whereas traditional modes of governance assume that power resides in identities or roles, decentralized network governance perceives power as residing in specific and changing relationships. Power can thus reside in every actor from individuals, corporations, or the state, depending on the relationship between these actors requiring governance. In different roles and relationships, multiple actors can possess each of the novel network powers. Regarding the concept of fluid power, and differing from other governance modes where roles are defined a priori, Mode 3 governance tacitly implies power through being an actor in a networked environment. This form power is a function of connectivity. In social network analysis, this kind of power is referred to as centrality of an actor in the network. Power in the form of connections allows actors to define their own role by choosing alliances dependent on the issues that are at stake. The example of voting behavior regarding finding consensus around hard forks is a case in point. By choosing alliances, networked actors assume governance functions within the network.

In order to illustrate this, we can take DAOs as an example. To qualify as a DAO, organizational governance on the blockchain needs to implement voting rights that determine the autonomous execution of smart contracts when certain conditions have been met, e.g., absolute majority or agreement of certain stakeholders 
and certain external conditions. "[The] DAO as an entity acts independently and cannot be influenced by external forces. The organization and its open-source code are fully transparent and therefore incorruptible. The functionalities and program rules are written in code and maintained on the blockchain" (Kondova and Barba, 2019). Any actor in the blockchain can submit a proposal that will be automatically executed if the consensus mechanism is triggered by the actors in the blockchain network. This ensures that all actors are voters and proposal-submitters at the same time: a clear case for networked power. At the same time, "The DAO" project in 2016 at ETH-Zurich illustrated that network power - the power over a network for standard setting - can act as a last resort fail-safe. In this case, the $\$ 250$ million raised through the Ethereum network upon the launch of the project were stolen, but then through the fail-safe of the hard fork, they were recovered. DuPont elaborates on this as follows:

\begin{abstract}
However, shortly after the minimum 2-week "debating" period, on June 17, 2016, The DAO's code was "exploited" by an unknown individual. This exploit used unintended behavior of the code's logic to rapidly drain the fund of millions of dollars' worth of ETH tokens. Immediately, Slock.it, the leaders of the Ethereum platform, numerous crypto-currency exchanges, and other informal technical leaders stepped in to stem the bleeding - shutting down "exits" through the exchanges, and launching counter-attacks. It is at precisely this point that we see the vision of future governance structures break down, and devolve into traditional models of sociality - using existing strong ties to negotiate and influence, argue and disagree - all with nary a line of code in sight. In the end, the whole project was disbanded, with an inglorious "hard fork" rolling back the ostensibly "immutable" ledger (DuPont, 2017, p. 158).
\end{abstract}

While DuPont describes The DAO experiment ultimately as a failure, it does illustrate our perspective on decentralized network governance. Actors on different levels of the blockchain solution were able to exert different governance roles successfully. This took place inside the DAO and, on a higher level on the Ethereum network, through a "hard fork." As such, this DAO hack exemplifies the fact that blockchain does impose specific governance elements by virtue of its on-chain governance structures. In its ideal form, blockchain can resemble a liberal notion of a positivist legal order. In times of crises, as the DAO hack certainly represents, governance structures resorting to off-chain solutions might more closely resemble political governance outside of the legal order that the blockchain itself represents (Reijers et al., 2018). However, the off-chain solution is also a governance structure that is based on the design of the blockchain and thus represents a meta-governance structure. In the example of The DAO, as well as in other cases of consensusfinding for a hard fork, actors decide on changing the rules on a meso-level, i.e., off-chain but bound by the design of the technology for their range of possible actions. On a metalevel, namely, the technological infrastructure, the possibility of this decision to hard-fork is implied by the design of the blockchain technology. Were the technology designed in a way that would preclude the option of a hard fork, stakeholders would not even be able to contemplate the hard fork as an option. This is also an example of how technology tacitly imposes norms of governance, and how on-chain and off-chain governance are entangled together. It also shows that governance mechanisms of DLT are design features rather than sine qua non-conditions.

Therefore, as illustrated above, off-chain mechanisms that distribute tasks and obligations are typical for this sort of governance imposed by digital networks. This characteristic is independent of the identity of an actor. But it depends on the specific type of power of an actor and its role in a specific policy domain. Decentralized network governance, thus, does not presuppose a certain delineation between actors as pre-given, but assumes that actors' rights, obligations, and regulatory authorities change depending on the function and role they assume in relation to other actors. The two most crucial new forms of power are the power to constitute and reprogram networks (networkmaking power) and the power to connect and ensure cooperation within networks (networked power) (Castells, 2011). These two powers are exerted by new private actors within the digital domain of blockchain-based solutions. Within the case of The DAO project, examples of these new actors are as follows: Slock.it, the leaders of the Ethereum platform, numerous crypto-currency exchanges, and other informal technical leaders.

Since the crucial elements of network power reside with private (corporate) actors, it is important to integrate third parties into the theoretical model of decentralized network governance. For instance, governance roles on the blockchain (on-chain governance) or outside and around a blockchain solution (off-chain governance), can be performed by a myriad of different actors. These take on a specific role in concrete situations. Effective governance of power relationships thus requires alliances to be brokered between actors in order to match the exerted power of the dominant or deviant actors. This necessitates new associations in specific and single-issue areas, in order to establish a new and more equal balance of power. In other words, a pre-legal political realm is given space within the network of actors that surrounds DLT solutions. Third parties can play governance roles via education and providing information, acting as watchdogs and private enforcers, aiming to prevent harm and reforming legal rules. This resembles the structures of Mode 2 governance. The difference, however, is that these governance tasks can be performed in alliances vis-à-vis an actor who exerts greatest power; i.e., governance with, alongside, and against states and legal rules.

The actors who regulate, make, have to adhere to, and are regulated by policies vary in a fluid way. Even if the state does not have much on-chain power as the governing actor in Mode 3 , off-chain, it can play a more crucial role in empowering different actors by enabling the clustering of interest groups. This implies that within decentralized network governance, roles are empowered through relationships rather than by specific identities or policy areas. States can empower actors by providing access to information, improving the legal standing of non-state actors, and (in particular) raising the position of those who represent minorities or subordinate groups vis-à-vis increasingly powerful actors. Furthermore, due to its centralized position, the state can assume brokerage positions and close structural holes. Mode 3 governance also empowers individuals to enter into new relationships outside of the traditional modes of 
governance. Examples of this are digital pressure groups, who often supersede national borders, jurisdictions, and governance institutions. Through the use of social networks and other technological instruments, these interest groups voice concern, empower others, enforce and protect rights, reform law, and prevent harm by pressuring others to perform their obligations adequately. Logically, three strategies of decentralized network governance can be conceptualized:

(1) Platform strategy, in which crowds, e.g., interest groups or one-issue parties, are enabled by the state (off-chain) to critique and protest about powerful actors within the network (on-chain). In this role, the state can also facilitate the education of under-informed individuals and institutions.

(2) Private strategy, in which crowds cooperate within a network to achieve certain goals, put certain proposals forward, or correct and counterbalance other power brokers in the network.

(3) Legal strategy, in which the state or the designer of a technology, e.g., the DAO with regard to blockchain technologies, enables actors to effectively protest against and critique powerful actors. This is done by exempting them from legal requirements when there are grave power imbalances in specific relationships.

The common effect of these strategies is that they enable deliberation among the relevant actors and allow weaker actors to join forces to counterbalance more powerful ones. In a context where traditional governance fails, decentralized network governance opens up a space for contestation in which actors in concert govern each other. The available means range from educational pursuits to legalizing otherwise illegal means such as white-hat hacking or other forms of protest. Such governance has the best chances to achieve effective regulation of power relationships and can trigger increased and better self-regulation. This can be done, for instance, by motivating powerful actors to initiate more detailed codes of conduct in concert with societal actors, or by improving international public collaboration regarding the protections of rights for weaker parties in the digital domain.

\section{METHODOLOGICAL CONSIDERATIONS}

In decentralized networked governance, actors within policy networks engage in a networked structure rather than a hierarchical or horizontal structure. The term "decentralized network governance," therefore, as foreshadowed with Castells's approach, is not only a descriptor of the changes in the structures that we have witnessed in the ongoing trend from Mode 1 to Mode 3. We use this term also as a signifier to indicate that network theory could provide a valuable analytical and practical approach. In the following paragraphs, we will briefly outline the implications of adapting social network theory and methods to this domain.

As suggested for the practice of policy-making, programming, and project design, social network analysis can provide many insights. More can be understood about patterns of interaction, structural holes, diffusion of information, clusters and groups within a network, cooperation and conflict among actors, and the effects that the emergence of new actors, as well as the disappearance of existing actors has on a network (Zwitter, 2016). Approaching decentralized network governance from the perspective of social network theory becomes particularly compelling in analogy to the ideas underpinning social networks, as formulated by Simmel (2011, p. 4):

A collection of human beings does not become a society because each of them has an objectively determined or subjectively impelling lifecontent. It becomes a society only when the vitality of these contents attains the form of reciprocal influence; only when one individual has an effect, immediate or mediate, upon another, is mere spatial aggregation or temporal succession transformed into society.

Exactly this kind of vitality and reciprocal influence can be witnessed in off-chain governance, which lends a political dynamic. Likewise, a network of actors does not become a governance-relevant policy network because of their individual salient positions, but because of their interactions, the identity they portray in specific policy circles, and the respective leverage they have vis-à-vis other actors, depending on the subject matter. Translating this to the case of off-chain governance, we have seen in The DAO case that roles of actors changed from beneficiary to regulator when moving from on-chain to off-chain governance.

Through the lens of social network analysis, the role and power of actors within a decentralized network are functions dependent on whether actors can influence other actors or whether they can leverage their positions through different forms of brokerage. The nodes (actors) and ties (connections) ultimately determine policy-making power. Identity and role are isolated; permanent aspects of power are irrelevant in this context. For analytic purposes, the digital network represents "a specific set of linkages among a defined set of persons [actors], with the additional property that the characteristics of these linkages as a whole may be used to interpret the social behavior of the persons involved" (Mitchell, 1969, p. 2). That means, on the one hand, that understanding the properties of a digital network has analytic benefits for understanding the underlying patterns of social structure and for explaining behavior and power (Wellman, 1988).

On the other hand, however, it also has policy-making implications. Understanding the power relationships that emerge from a network structure helps in assigning responsibilities to key players and developing appropriate governance mechanisms. As a first step toward the analysis and structuring of a network, such as actors in a blockchain network, power needs to be understood differently. In network theory, power is considered as the ability to leverage one's position vis-à-vis ties with other actors. Power becomes a function of centrality. It suffices to say that different forms of centrality (degree, closeness, and betweenness centrality) provide different methods of analysis of the network (Knoke and Yang, 2008). Different centrality functions help to identify the right actors, which can leverage their position adequately. Within decentralized network governance, the centrality of 
actors is the relevant aspect of power relationships in assigning responsibilities and developing governance mechanisms.

Of particular utility for decentralized network governance is the clustering coefficient. Defined in social network theory, this measure concerns the degree to which actors in a social or policy network cluster together. It is based on the empirical finding that, in social networks, members of distinct groups share a more tight-knit network among each other. Within a network, distinct groups are thus characterized by a high density of ties among a set of nodes. The clustering coefficient can be used to identify groups within a larger digital network that were previously unknown and that might either leverage their coordinated power vis-à-vis the rest of the network, or provide specific services. For example:

\begin{abstract}
"Core Ethereum developers were in favor for such a hard-fork in order to return stolen funds. Most miners followed their lead. However, a minority of miners rejected the controversial idea to change immutable transactions and continued mining the old blockchain. This divided Ethereum into two co-existing blockchains, the new one, Ethereum (ETH), and the old one, Ethereum Classic (ETC)." (Friebe, 2017)
\end{abstract}

This illustrates that while technically everybody has an independent vote, the leverage of prestige and networking power (see Castells's classification above) can determine the outcome of off-chain voting and have direct on-chain effects as the split into two Ethereum blockchains illustrates. At the same time, increasingly larger mining pools are being established in order to share processing power and, thus, the mined benefits. Furthermore, we are increasingly witnessing single private-sector actors establishing themselves in various blockchain domains by using large server farms, in order to maximize profit. These developments indicate that centralization and clustering are taking place, which requires further analysis and potentially governance mechanisms to regulate their effect.

In addition to the three strategies of decentralized network governance mentioned in the previous section, the brokerage positions within policy networks in particular can be leveraged to achieve desired outcomes or to avoid undesired ones. Brokerage positions appear when we have a look at different groups in the policy network. According to Gould and Fernandez (1989), actors can:

(1) coordinate within a group (coordinator),

(2) consult members of a group as an outsider (consultant),
(3) prevent or facilitate outsiders to gain access to a group (gatekeeper),

(4) represent the group to the outside (representative), or

(5) mediate between separate groups (liaison).

As illustrated above, network theory and its methodical application through social network analysis can, thus, provide concrete insights into existing blockchain and DLT applications. This methodology can be applied to both on-chain and offchain dynamics. It can also be used to design smarter digital networks and assign roles to actors depending on their centrality and brokerage positions, as well as identify groups within a larger network that can fulfill certain functions (such as counterbalancing powerful single actors). Methodologically, social network analysis might have a central role to play in the further development of a theoretical framework regarding decentralized network governance. Ultimately, this may help contribute toward the effective governance of the digital domain.

\section{CONCLUSION}

Over the years, governance mechanisms have adapted due to globalization, increased technical specialization, and functional differentiation. However, governance also needs to adapt to the technical innovations of the digital domain in general, and to the increasing use of blockchain technology in particular. Due to the use of and reliance on digital networks, DLT and blockchain technology are increasingly shaping our societies and power relationships. Even at a time when their full potential is still debated and undetermined, the effects of technologies as governance instruments are increasingly tangible. In the present article, we have provided the first systematic steps toward the necessary reconceptualization of governance as applicable to societies increasingly shaped by digital networks and blockchain technology. We have proposed a framework of decentralized network governance. As illustrated in this paper with cases from blockchain technology, decentralized network governance is by no means limited to DLT. It applies equally to all modern power relationships that are characterized by the preponderance of private actors that provide networks of communication for other private actors.

In order to set the stage and explain the necessity of a reconceptualization of governance, we started by outlining the

\begin{tabular}{|clll|}
\hline MODE & ALTERNATIVE TERMS & POWER RELATIONS & FUNCTION \\
\cline { 2 - 3 } & Old governance & Static & Identity-based \\
Mode 2 & New governance (or & Static or variable (depending on & Role-based \\
& network governance) & whether roles are fixed) & \\
Mode 3 & Decentralized network governance & Dynamic & Fluid \\
FIGURE 4 | Overview of modes of governance. & & \\
\hline
\end{tabular}


transformative nature of blockchain technology as a case within and representative of the larger implications of the changes experienced in the digital and online domain. It became apparent that DLT has concrete, disruptive effects on policymaking when examining the impact on existing actors and the emergence of new ones. Furthermore, for the purpose of developing a stringent framework for decentralized network governance, old (Mode 1) and new (Mode 2) governance were analyzed, focusing on power, identity, and the roles that actors play within these forms of governance. Mode 1 describes traditional, hierarchical governance with fixed identities (states, corporations, and citizens). Mode 2 describes a more horizontal form of governance with fixed roles depending on power and expertise (see Figure 4). Within Mode 2 governance, one can identify three forms: (a) public-private governance, (b) non-autonomous self-governance, and (c) autonomous selfgovernance.

To illustrate this, we took blockchain technologies and DAOs specifically as examples. We concluded that these examples are inaccessible to both traditional forms of governance. The core critique is that both modes of governance do not take into account the fact that the roles of actors in DLT-based solutions are constantly changing, and that power is context-specific and relational. This became apparent in the off-chain solution sought to remedy the DAO hack. In order to capture this new form of governance, which is also applicable in all sorts of digital networks, we propose the concept of decentralized network governance. This new mode of governance is characterized by the changing and multiple roles of actors, and the necessity to identify roles depending on network clusters and policy domains. This new perspective on governance as networked but decentralized opens up new policy mechanisms such as the design of new platforms for counterbalancing emergent digital actors. Network-making power facilitates the provision of such platforms for interest groups, tech-brokers, and private citizens, as well as actors with weaker power. Whereas onchain governance can impose a mode of governance explicitly, off-chain governance can assume such governance structures tacitly. This governance structure in technology networks displays the fluid features that characterize decentralized network governance.

\section{REFERENCES}

Balva, C. (2017). La Blockchain: Réinventer les rapports de confiance. https://www. youtube.com/watch?v=JID9c-MABis

Bevir, M. (2010). Democratic Governance. Princeton, NJ: Princeton University Press.

Brown, I., and Marsden, C. (2013). Regulating Code: Good Governance and Better Regulation in the Information Age. Massachusetts, CA: MIT Press.

Castells, M. (2000). The Rise of the Network Society. Oxford: Blackwell.

Castells, M. (2011). A Network Theory of Power. Int. J. Commun. 5, 773-787.

Chandler, D. (2015). A World without Causation: Big Data and the Coming Age of Posthumanism. Millenn. J. Int. Stud. 43, 833-851. doi: 10.1177/ 0305829815576817

Chohan, U. W. (2017). The Decentralized Autonomous Organization and Governance Issues. SSRN Electronic Journal. Available online at: https://ssrn. com/abstract=3082055 (accessed March 15, 2020).
It would have gone beyond the scope of this article to further unearth empirical material in the blockchain domain to flesh out the theoretical framework presented here. Therefore, it would be worthwhile to further investigate whether the interaction between on-chain and off-chain governance does indeed lead to specific governance dynamics. If the future of governance is indeed one of changing roles and power alliances, we should expect to see increasingly fluid dynamics within and surrounding digital networks. Such fluidity could express itself merely as users of the network banding together and increasingly defining the network. It could, however, also take explicit forms of governance within set rules of the network. This would depend on whether the network allowed for such decisions itself (e.g., on-chain) or whether it required extraordinary measures to be taken outside the network (e.g., off-chain, or alternative platforms).

Hence, decentralized network governance, as a new Mode 3 governance, allows for the conceptualization of new forms of regulation of digitalized social affairs. This is illustrated by the multiple uses of blockchain for logistic, financial or contractual purposes, which acknowledge the fluidity of roles of actors in and around blockchain networks. It recognizes that traditional means of command-and-control governance have little use concerning radically democratized platforms. This conception of a third form of decentralized, yet networked, governance gives concrete indications of the utility of social network analysis with regard to policy-making and the design of governance tools in the digital domain.

\section{AUTHOR'S NOTE}

Figures 1-3 as well as parts of the text have been translated and republished with permission of the publisher from Hazenberg and Zwitter (2017).

\section{AUTHOR CONTRIBUTIONS}

All authors listed have made a substantial, direct and intellectual contribution to the work, and approved it for publication.

Colombi-Ciacchi, A. (2014). Judicial Governance in Private Law through the Application of Fundamental Rights. Austr. Law J. 1, 120-134.

Dahl, R. (1957). The Concept of Power. Sys. Res. Behav. Sci. 2, 201-215.

DuPont, Q. (2017). "Experiments in algorithmic governance-A history and ethnography of "The DAO," a failed decentralized autonomous organization," in Bitcoin and Beyond: Cryptocurrencies, Blockchains, and Global Governance (, Ed Edn, ed. M. Campbell-Verduyn (Abingdon: Routledge), 157-177. doi: 10.4324/9781315211909-8

Friebe, T. (2017). Ethereum: Governed by a benevolent dictator? Medium. https://medium.com/blockchainspace/ethereum-governed-by-a-benevolentdictator-2a2be8aa331a.

Goodman, M. (2015). Future Crimes: Everything is Connected, Everyone Is Vulnerable and What We Can Do About It. Knopf. New York: Doubleday Publishing Group.

Gould, R. V., and Fernandez, M. R. (1989). Structures of Mediation: A Formal Approach to Brokerage in Transaction Networks. Sociol. Methodol. 19, 89-126. 
Hacker, P., and Thomale, C. (2018). Crypto-Securities Regulation: ICOs, Token Sales and Cryptocurrencies under EU Financial Law. Eur. Comp. Financ. Law Rev. 15, 645-696. doi: 10.1515/ecfr-2018-0021

Hazenberg, J. L. J., and Zwitter, A. (2017). Network governance im big data- und Cyber-Zeitalter. Z. Evangelische Ethik 61, 184-209. doi: 10.14315/zee-20170305 (accessed March 16, 2020).

Hsieh, Y.-Y., Vergne, J.-P., Anderson, P., Lakhani, K., and Reitzig, M. (2018). Bitcoin and the rise of decentralized autonomous organizations. J. Organiz. Des. 7, 14. doi: 10.1186/s41469-018-0038-1

Klijn, E. H. (2008). Governance and Governance Networks in Europe. Pub. Manag. Rev. 10, 505-525.

Knoke, D., and Yang, S. (2008). Social Network Analysis. Thousand Oaks (CA): SAGE.

Kondova, G., and Barba, R. (2019). Governance of Decentralized Autonomous Organizations. J. Mod. Account. Audit. 15, 406-411. doi: 10.17265/1548-6583/ 2019.08.003

Kooiman, J. (2003). Governing as Governance. Thousand Oaks (CA): SAGE.

Koppenjan, J., and Klijn, E. H. (2004). Managing Uncertainties in Networks. Abingdon: Psychology Press Routledge.

Lessig, L. (2000). Code Is Law. Harvard Magazine. https://harvardmagazine.com/ 2000/01/code-is-law-html.

Levi-Faur, D. (2012). "From "Big Government" to "Big Governance," in The Oxford Handbook of Governance, ed. D. Levi-Faur (Oxford: Oxford University Press), 3-18.

Lewis, J. M. (2011). The Future of Network Governance Research: Strength in Diversity and Synthesis. Pub. Administr. 89, 1221-1234. doi: 10.1111/j.14679299.2010.01876.x

Lobel, O. (2012). "New Governance as Regulatory Governance," in The Oxford Handbook of Governance, ed. D. Levi-Faur (Oxford: Oxford University Press), 65-82.

Manyika, J., Chui, M., Brown, B., Bughin, J., Dobbs, R., Roxburgh, C., et al. (2011). Big data: The next frontier for innovation, competition, and productivity (McKinsey Global Institute-May 2011). http://www.mckinsey.com/businessfunctions/digital-mckinsey/our-insights/big-data-the-next-frontier-forinnovation

Mayntz, R. (1998). New Challenges to Governance Theory. Italy: European University Institute.

Mayntz, R. (2003). From Government to Governance: Political Steering in Modern Societies. Summer Academy on IPP, Wuerzburg 7-11 September. http://www.ioew.de/govemance/english/veranstaltungen/Summer_ Academies/SuA2Mayntz.pdf

Metcalf, J., and Crawford, K. (2016). Where Are Human Subjects in Big Data Research? The Emerging Ethics Divide. Big Data Soc. 3, 1-14.

Mitchell, J. C. (1969). Social Networks in Urban Situations: Analyses of Personal Relationships in Central African Towns. Manchester: Manchester University Press.

Murray, R. W. (2011). Magnanimity and Rationality: Exploring How the Institutions of International Society Are Implemented. Paper Presented at the Annual Meeting of the International Studies Association Annual Conference "Global Governance: Political Authority in Transition", Le Centre Sheraton Montreal Hotel, MONTREAL, QUEBEC, CANADA, Mar 16, 2011. http://Www. Allacademic.Com/Meta/P501727_index.Html.
Nakamoto, S. (2008). Bitcoin: A Peer-to-Peer Electronic Cash System. Available online at: Www.Cryptovest.Co.Uk (accessed March 15, 2020).

Provost, F., and Fawcett, T. (2013). Data Science and Its Relationship to Big Data and Data-Driven Decision Making. Big Data 1, 51-59. doi: 10.1089/big.2013. 1508

Quiniou, M. (2019). Blockchain: The Advent of Disintermediation. John. Hoboken, NJ: Wiley.

Reijers, W., Wuisman, I., Mannan, M., De Filippi, P., Wray, C., Rae-Looi, V., et al. (2018). Now the Code Runs Itself: On-Chain and Off-Chain Governance of Blockchain Technologies. Vienna: Topoi.

Rhodes, R. A. W. (1996). The New Governance: Governing without Government. Polit. Stud. 44, 652-667. doi: 10.1111/j.1467-9248.1996.tb01747.x

Rhodes, R. A. W. (1997). Understanding Governance: Policy Networks, Governance, Reflexivity, and Accountability. Cambridge: Cambridge University Press.

Richards, N. M., and King, J. H. (2013). Three Paradoxes of Big Data. Stanf. Law Rev. 66, 41-46. doi: 10.1186/s12913-017-2416-8

Sand, I.-J. (2004). "Polycontextuality as an Alternative to Constitutionalism," in Transnational Governance and Constitutionalism, Eds Edn, eds C. Joerges, I.-J. Sand, and G. Teubner (Oxford: Hart Publishing), 42-66.

Scharpf, F. (1999). Governing in Europe: Effective and Democratic?. Oxford: Oxford University Press.

Simmel, G. (2011). Georg Simmel on Individuality and Social Forms. Chicago: University of Chicago Press.

Van Kersbergen, K., and Van Waarden, F. (2004). "Governance" as a Bridge Between Disciplines: Cross-disciplinary Inspiration Regarding Shifts in Governance and Problems of Governability, Accountability and Legitimacy. Eur. J. Polit. Res. 43, 143-171. doi: 10.1111/j.1475-6765.2004.00149.x

Warburg, B. (2016). How the blockchain will radically transform the economy. https://www.ted.com/talks/bettina_warburg_how_the_blockchain_will_ radically_transform_the_economy/up-next?language $=$ en

Wellman, B. (1988)). "Structural Analysis: From Method and Metaphor to Theory and Substance," in Social Structures: A Network Approach, ed Edn, eds B. Wellman, D. Stephen, and Berkowitz (Cambridge: Cambridge University Press), 19-61.

Zwitter, A. (2015). Big Data and International Relations. Ethic. Int. Aff. 29, 377-389. doi: $10.1017 /$ S0892679415000362

Zwitter, A. (2016). Humanitarian Intelligence - A Practitioner's Guide to Crisis Analysis and Project Design. New York. London: Rowman \& Littlefield.

Zwitter, A., and Boisse-Despiaux, M. (2018). Blockchain for humanitarian action and development aid. J. Int. Hum. Act. 3, 16. doi: 10.1186/s41018-0180044-5

Conflict of Interest: The authors declare that the research was conducted in the absence of any commercial or financial relationships that could be construed as a potential conflict of interest.

Copyright $(2020$ Zwitter and Hazenberg. This is an open-access article distributed under the terms of the Creative Commons Attribution License (CC BY). The use, distribution or reproduction in other forums is permitted, provided the original author(s) and the copyright owner(s) are credited and that the original publication in this journal is cited, in accordance with accepted academic practice. No use, distribution or reproduction is permitted which does not comply with these terms. 